\section{Equilibrios vitales} A vital balance

El artículo comentado ${ }^{1}$ es un balance -valga el juego de palabras- respecto de la repercusión que tuvo uno anterior del primero de sus autores. ${ }^{2}$ El tema se inscribe dentro de la creciente literatura sobre burnout en medicina y otros trabajos sobre la auto-percepción de los médicos de las condiciones de su práctica. Desde el artículo de medición de burnout de Christina Maslach a comienzos de la década de los ochenta -para sugerir un límite temporal- el tema creció exponencialmente, en cierta medida, a tenor de una realidad cada vez más estresante para los profesionales de la salud. ${ }^{3}$ Es fácil encontrar un acceso actualizado y confiable a la creciente literatura sobre este círculo de cuestiones. ${ }^{4-6}$

El editorial que se comenta -tanto como el trabajo original de Schwingschakl y los que se publicaron como reacción a éste- tienen un tono auto-referencial característico, exigido por la naturaleza del tema. Básicamente, Schwingschackl y Anand sostienen que la noción de "equilibrio entre trabajo y vida" no es útil, porque plantea una disyuntiva falsa. Sin embargo, reconocen que tal concepto está muy presente como preocupación de los colegas. Como los autores, considero este tema de enorme importancia. Pero el tipo de planteo formulado abre a interrogantes que llevan a perspectivas amplias de saludable discusión y opinión profesional.

Lo primero que habría que decir es que estas cuestiones son, digamos, "sociedad-dependientes" en alto grado. Ciertamente, las condiciones de trabajo y de vida privada de la costa oeste de Estados Unidos parecen difícilmente comparables con las que pueden verificarse en los grandes centros urbanos de la Argentina. Un mundo globalizado y altamente interconectado puede llevar a una ilusión de homogeneidad que es sólo eso, un espejismo, porque las realidades cotidianas, de trabajo y personales (work y life) son diferentes. Esto no quiere decir que no haya muchas cosas en común, por ejemplo, la creciente conciencia sobre las crisis vitales y la agudización de condiciones cada vez más complejas (algunos dirían "inhumanas") del ejercicio profesional. Lo que es diferente es el contenido de esas crisis, cuáles son sus significados y cómo se puede responder a ellas. Burn out puede ser un fenómeno común, pero no es lo mismo estar "quemado" por la presión institucional y las demandas de alta competitividad en el modelo de carrera hospitalaria y de investigación clínica que podría darse en Los Angeles, a tener que hacer tres guardias por semana en condiciones de riesgo físico, sin demasiado futuro y en un contexto social crónicamente inestable. Ni qué decir que la manera de concebir proyectos de vida, en muchos casos de familia, son también muy diferentes en ambos hemisferios, en tanto estas auto-imágenes de futuro crecen en el espesor de valores culturales (espero no se tome a mal si aclaro que afirmo esto sobre la base de la experiencia personal).

En el horizonte, se perfilan dos temas intimidantes por demasiados vastos; me voy a refugiar en mi exceso de edad para hacerlo. El primero es cómo la medicina generada en Estados Unidos a partir de la segunda postguerra se volvió un modelo hegemónico o, desde el otro lado, como las tradiciones médicas locales ensayaron (o no) articularse con este modelo. Esto quizás no sea tan relevante en cuestiones clínicas o de investigación básica o clínica o de la práctica clínica, pero lo es en todos aquellos aspectos que hacen a la esencia social de la medicina. Esta es la segunda cuestión: en los años sesenta, la "medicina social" era un enfoque más; quien en la segunda década del siglo XXI no entienda que la medicina es, ante todo, un hecho social (aunque no sólo eso, claro) está muy desorientado. La vida de una pediatra en la ciudad de Buenos Aires no es la vida de una médica en Stanford. ¿Pueden extrapolarse las conclusiones? Tiendo a ser más bien escéptico. Porque se estaría pasando por alto hasta qué punto el ejercicio profesional depende de estructuras económicas, sociales y, por supuesto, profesionales particulares de cada comunidad.

Las nociones de "vida" y "trabajo" usadas por los autores del artículo, ¿son homologables a sus análogos locales? Se trata de la misma "vida", del mismo "trabajo". ¿No es más bien que, como los mismos autores señalan, estos conceptos son en realidad "constructos" que manejamos para tratar de entendérnoslas con nuestra actividad y, en tanto tales, están edificadas con los materiales del mundo inmediatamente circundante en que nos toca vivir? Y si nos asomamos a análisis conceptuales más finos, uno podría preguntarse: ¿el "trabajo" acaso no es "vida"? ¿En qué se funda 
este dualismo "vida-trabajo", del que se parte, para luego negarlo? Una cosa son las charlas informales, donde se habla de estas cosas entre melancolías y café quemado, y otra los análisis que resultan en artículos publicados en journals. ¿Se puede transitar de una dimensión a la otra sin solución de continuidad? ¿No entramos más bien en el mundo de la auto-percepción de valores y situaciones con alto contenido subjetivo? Es por lo menos tema de debate hasta qué punto este tipo de cuestión es susceptible de tratamiento estadístico -una de las virtudes del editorial comentado es que, en ese respecto, se queda de este lado del cerco.

En fin, como los autores señalan, quizás lo más interesante sea la discusión misma, no los términos en que ésta está planteada -que a mi juicio son materia de deliberación por las razones señaladas. Porque la cuestión existe: ¿qué es la vida de un pediatra hoy en día, la vida trabajada y la vida vivida, aquí? (y sí, admito que el dualismo "vidatrabajo" me genera sospechas) ¿Qué posibilidades de florecimiento o planificación personal existen en las distintas formas de ser pediatra o ejercer la pediatría en la Argentina? Más aún y desde un lenguaje que en tanto tal, está preñado de preconceptos: ¿es lo mismo decir "ser pediatra" que decir "ejercer la pediatría"? Todo esto merece ser discutido, y quizás de manera formal. Demás está decir que la experiencia aportada por la literatura internacional es muy valiosa. Pero no habría que perder de vista que estas cuestiones, que cada vez se nos presentan como más agudas, tienen la milenaria edad de la profesión médica $-y$, de hecho, de la humanidad.

\section{Dr. Miguel de Asúa} CONICET-UNSAM

http:/ / dx.doi.org/10.5546/aap.2018.308

Texto completo en inglés:

http: / / dx.doi.org/10.5546/aap.2018.eng.308

Cómo citar: De Asúa M. Equilibrios vitales. Arch Argent Pediatr 2018;116(5):308-309.

\section{REFERENCIAS}

1. Schwingshackl A, Anand KJS. Editorial: Work-Life Balance: Essential or Ephemeral? Front Pediatr 2017; 5:108.

2. Schwingshackl A. The Fallacy of Chasing after Work-Life Balance. Front Pediatr 2014; 2:26.

3. Maslach C, Jackson SE. The measurement of experienced burnout. J Organ Behav 1981; 2(2):99-113.

4. Mahan JD. Burnout in Pediatric Residents and Physicians: A Call to Action. Pediatrics 2017; 139(3):e20164233.

5. BaerTE, Feraco AM, Tuysuzoglu SagalowskyS, etal.Pediatric Resident Burnout and Attitudes Toward Patients. Pediatrics 2017; 139(3):e20162163.

6. West CP, Dyrbye LN, Erwin PJ, et al. Interventions to prevent and reduce physician burnout: a systematic review and metaanalysis. Lancet 2016; 388(10057):2272-81.

\section{Artículos seleccionados}

Los siguientes resúmenes y comentarios de trabajos seleccionados se encuentran disponibles en la versión electrónica de este número.

PEDIATRICS 2018; 141(5):e20173674

Validación externa de la regla de predicción clínica del PediBIRN para trauma cefálico abusivo (Pfeiffer $H$, et al. External validation of the PediBIRN clinical prediction rule for abusive head trauma)

Comentario: Dr. Juan Pablo Mouesca. Unidad de Violencia Familiar. Hospital General de Niños Dr. Pedro de Elizalde, Buenos Aires.

PEDIATRICS May 2018, Volume 141 / Issue 5

Resultados neuroconductuales a 11 años después de la administración de cafeína en neonatos para la apnea de la prematuridad (Mürner-Lavanchy IM, et al. Neurobehavioral outcomes 11 years after neonatal caffeine therapy for apnea of prematurity, for the caffeine for apnea of prematurity (CAP) Trial Group)

Comentario: Dr. José M. Ceriani Cernadas. Hospital Italiano de Buenos Aires. Sociedad Argentina de Pediatría.

PEDIATRICS 2018 Apr;141(4)

Lesiones por "hoverboard" y patineta en pediatría (Bandzar S, et al. Pediatric hoverboard and skate board injuries) Comentario: Dra. Ingrid Waisman. Comité de Prevención de Lesiones de la Sociedad Argentina de Pediatría. 